\title{
Comparative Survival of Sclerotia of Sclerotinia minor and $S$. sclerotiorum
}

\author{
B. M. Wu, K. V. Subbarao, and Y.-B. Liu
}

First and second authors: Department of Plant Pathology, University of California, Davis, U.S. Agricultural Research Station, 1636 E. Alisal St., Salinas, CA 93905; and third author: USDA-ARS, U.S. Agricultural Research Station, 1636 E. Alisal St., Salinas, CA 93905. Accepted for publication 19 February 2008.

\section{ABSTRACT}

Wu, B. M., Subbarao, K. V., and Liu, Y.-B. 2008. Comparative survival of sclerotia of Sclerotinia minor and S. sclerotiorum. Phytopathology 98:659-665.

Survival of sclerotia of Sclerotinia minor and S. sclerotiorum was compared in irrigated fields during the summer in two major lettuce production areas in California. More than $50 \%$ sclerotia of S. sclerotiorum compared with 4 and $35 \%$ of S. minor remained viable after 24 weeks of burial at 15 and $5 \mathrm{~cm}$ depths, respectively, in the San Joaquin Valley while $>80 \%$ of sclerotia survived in the Salinas Valley for both species. The results explain in part the lower infections from $S$. minor in the San Joaquin Valley. To identify factors that contribute to the rapid decline in the viability of sclerotia, the effects of soil moisture, temperature, and oxygen levels were studied in laboratory. More than
$90 \%$ of sclerotia of both species survived for at least 3 months in sterilized dry soils at temperatures between 15 and $40^{\circ} \mathrm{C}$. Soil moisture did not affect survival at 15 and $25^{\circ} \mathrm{C}$. At $35^{\circ} \mathrm{C}$, however, survival rates were significantly lower at high $(-0.3$ to $-0.01 \mathrm{MPa})$ water potential than at low $(<-1.0 \mathrm{MPa})$ water potential. Incubation under ultralow oxygen concentration $(0.01 \%)$ significantly reduced survival of sclerotia in nonautoclaved moist soils at $25^{\circ} \mathrm{C}$, with less than $2 \%$ sclerotia surviving over 4 weeks compared with about $45 \%$ sclerotia surviving at the ambient oxygen level $(21 \%)$. The combination of high temperature, high soil moisture, and reduced oxygen in irrigated fields contribute to the lower survival of both Sclerotinia species and the responses of the two species to these conditions shape their relative geographical distribution.

Additional keywords: lettuce drop, irrigation.
Sclerotinia sclerotiorum (Lib.) de Bary and S. minor Jagger are two plant pathogens of diverse hosts including many economically important crops $(10,28,32)$. Lettuce drop, caused by the two pathogens, is one of the most destructive lettuce diseases, causing severe yield losses worldwide $(8,24,27,32,38,39)$. In California, lettuce drop causes about 5\% average yield losses and about $\$ 100$ million economic loss $(32,45)$ with as much as $>30 \%$ yield losses in heavily infected fields. In the San Joaquin Valley, California, $S$. minor has remained a minor pathogen although lettuce drop caused by this species has been observed there frequently (45). It is unclear why lettuce drop caused by S. minor has not become a serious threat to lettuce in the San Joaquin Valley. A better understanding of the factors that limit infections by this species in the San Joaquin Valley may be useful for the management of lettuce drop in the areas like the Salinas Valley, California where lettuce drop is mainly caused by $S$. minor.

The disease cycles caused by the two pathogens exhibit many similarities as well as differences on lettuce. Both species mainly survive as sclerotia in soil, and infect lettuce either directly via eruptive germination or indirectly through ascospores produced from carpogenic germination of sclerotia $(1,2,6,7,14,23,30$, $31,39)$. Secondary inoculum within a season is not produced by either species on infected plants and therefore plant-to-plant spread occurs only through direct hyphal growth from infected tissues to adjacent healthy plants $(14,23)$. This usually occurs at very low frequencies and contributes little to the disease epidemics $(2,39)$. For $S$. sclerotiorum, lettuce plants are mainly infected by airborne ascospores from the carpogenic germination of sclerotia, and therefore disease incidence is usually sporadic and

Corresponding author: K. V. Subbarao; E-mail address: kvsubbarao@ucdavis.edu

doi:10.1094/PHYTO-98-6-0659

(c) 2008 The American Phytopathological Society dependent on weather conditions conducive to the production of apothecia $(31,45)$. In contrast, apothecia of $S$. minor have rarely been observed in production fields and their role in epidemics is limited $(16,21,22,39)$. Incidence of $S$. minor-induced lettuce drop is correlated with the density of sclerotia in soil $(14,23)$. Since the density of competent sclerotia (19) in soil is the most important factor affecting infections by S. minor, a better understanding of their survival in soil is essential to develop new methods for management of this disease.

Although sclerotium survival of the two species has been studied extensively, the results from field studies are inconsistent due to the complexity of soil environment. Davis (13) found that sclerotia of $S$. sclerotiorum near the soil surface remain viable for less than a year, but Young and Morris (46) reported that at least a 4-year rotation was needed for sunflower to be grown in fields with a history of Sclerotinia wilt. Adams and Ayers (6) reported that lettuce drop caused by $S$. minor could be successfully managed by a 4-year rotation with nonhost crops, but Schwartz and Steadman (35) reported that a 3-year crop rotation did not reduce sclerotia populations significantly, and the soil population of sclerotia did not increase even in fields where severe annual epidemics of white mold had occurred. Similarly, the soil populations of sclerotia in a bean field in New York remained about the same even after three consecutive years of severe epidemics of white mold (G. S. Abawi, unpublished data [2]). Ben-Yephet et al. (9) found that the number of sclerotia of S. sclerotiorum declined slowly over years following outbreaks of lettuce drop in four naturally infested fields.

Many factors affect survival of sclerotia of the two species. Adams (4) reported that a constant soil temperature of $35^{\circ} \mathrm{C}$ for 3 weeks or more reduced survival of sclerotia. Solarization, via increasing soil temperature, reduces viability of sclerotia of $S$. minor in the topsoil (44), and approximately $96 \%$ of sclerotia at 0 to $2 \mathrm{~cm}$ depth lose viability within 2 to 3 weeks following 
solarization. An 8-week solarization also reduces viability of $S$. sclerotiorum sclerotia buried in the soil at a depth of $10 \mathrm{~cm}$ (42). Viability of sclerotia also declines rapidly over time at high soil water potential (3). Moore (29) reported that nearly $100 \%$ of the sclerotia were killed when soil was flooded with water for 26 to 31 days. Imolehin and Grogan (23) found that sclerotia of $S$. minor survived better in dry than in moist soils, and better at shallow than at deeper soil profiles where higher moisture usually exists. Matheron and Porchas (25) reported that at $\geq-0.02 \mathrm{MPa}$, viable sclerotia decreased as soil temperature increased from 15 to $40^{\circ} \mathrm{C}$, no sclerotia were viable after 2 weeks at $40^{\circ} \mathrm{C}$, but the viability of sclerotia of both species remained relatively high in dry soil. Adams (5) found that temperature higher than $35^{\circ} \mathrm{C}$ and very low moisture (-116 MPa or lower) also reduced survival of sclerotia of $S$. minor, and the low soil moisture during the summer months $\left(6\right.$ to $\left.37^{\circ} \mathrm{C}\right)$ led to the decline in the number of sclerotia in the soil at the 0 to $2 \mathrm{~cm}$ depth.

The most significant factor affecting survival of sclerotia in soil may be biological. More than 30 species of fungi and bacteria have been implicated by various workers (6). Among them, Trichoderma hamatum and Coniothyrium minitans reduce survival of sclerotia, and are used as biocontrol agents for diseases caused by $S$. sclerotiorum and $S$. minor $(11,17,26,33)$. A significant negative association between viability of sclerotia and bacterial populations on sclerotia was also reported in field experiments (15).

Despite the plethora of reports described above and the suspected effect of oxygen concentration on survival of sclerotia, few studies have compared the survival of the two species or examined the role of oxygen in the survival of the species. Our objectives were to compare the survival of the two Sclerotinia species in irrigated fields in the San Joaquin and Salinas Valleys, to determine if survival is the factor limiting $S$. minor in the San Joaquin Valley, and to determine the major soil factors that affect survival of sclerotia of the two Sclerotinia species.

\section{MATERIALS AND METHODS}

Isolates used and production of sclerotia. Two isolates each of S. sclerotiorum (BS014 and BS001) and S. minor (SM1 and $\mathrm{SC} 2$ ) maintained on potato dextrose agar (PDA) plates were used to produce sclerotia for all experiments. Fresh potatoes were peeled and cut into 1 to $2 \mathrm{~cm}$ cubes and filled into 500-ml flasks

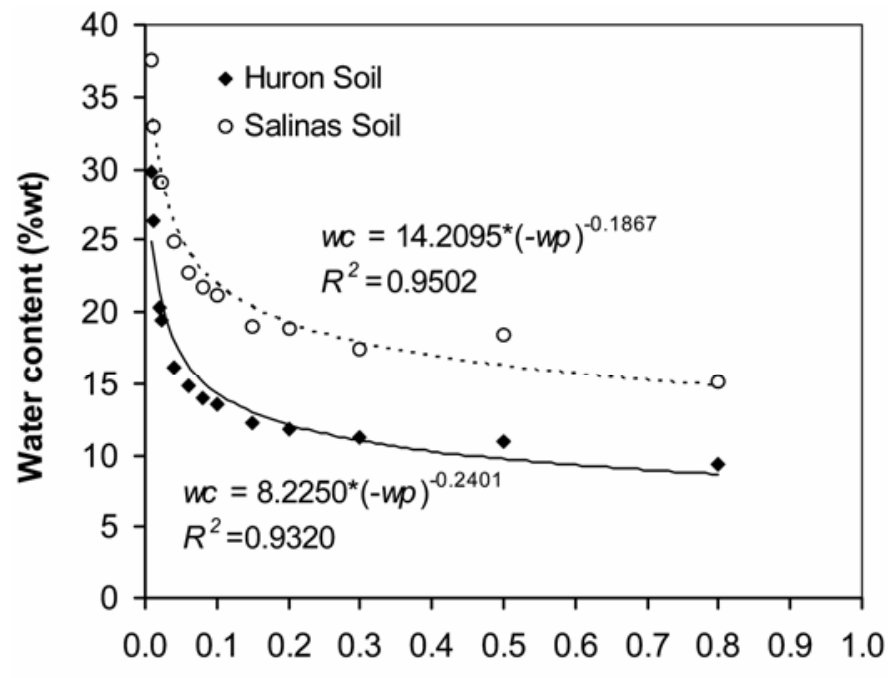

\section{Water Potential (-MPa)}

Fig. 1. Relationship between water content (\% dry weight) and water potential (MPa) for the two soils used in laboratory experiments, which were collected from fields at Huron (in the San Joaquin Valley) and Salinas (in the Salinas Valley). up to about $250 \mathrm{ml}$ and autoclaved for $30 \mathrm{~min}$ twice in $24 \mathrm{~h}$. After the potato pieces cooled down to room temperature, 5 to $6(0.5 \mathrm{~cm}$ $\times 0.5 \mathrm{~cm})$ culture plugs of individual isolates were transferred into the flasks. The inoculated potato pieces were incubated at room temperature (around $23^{\circ} \mathrm{C}$ ) and shaken every other day to promote uniform colonization of potato pieces. After potato pieces had been fully colonized by mycelia, the lid on the flasks was slightly opened to aerate the culture. About 3 weeks later, mature sclerotia were collected by washing off mycelia and remaining potato debris in a sieve. Sclerotia were then air-dried and stored at room temperature for use in experiments.

Survival of sclerotia of $S$. minor and $S$. sclerotiorum in the Salinas and San Joaquin Valleys. For each of two isolates of $S$. minor and $S$. sclerotiorum, 40 sclerotia were placed into a series of nylon mesh bags containing 40-ml nonsterilized pulverized soil (prepared as described later) from lettuce fields in the Salinas and San Joaquin Valleys. The bags were then buried at depths of 5 and $15 \mathrm{~cm}$ in two sprinkler-irrigated fields each in the San Joaquin and Salinas Valleys. At 0, 4, 8, 16, and 24 weeks after burial, a bag of sclerotia were retrieved for each treatment combination (valley $\times$ field $\times$ depth $\times$ species $\times$ isolate), the soil assayed by wet sieving (40) and the recovered sclerotia tested for viability as described below. The experiment was conducted twice, starting on 16 May 2000 and 15 May 2001, respectively. The experimental design was a split-split-split plot with valley as the mainplot factor, field as the sub-plot factor, depth as the sub-subplot factor, and species and isolate as the sub-sub-subplot factors.

Effects of temperature on survival of sclerotia. Soils collected from five different lettuce fields in the San Joaquin Valley were mixed, pulverized, sieved, and autoclaved as described below, then $35-\mathrm{ml}$ aliquots were dispensed into petri dishes. Forty sclerotia from each of the four isolates were buried into soil in each petri dish. Petri dishes with soils and sclerotia were incubated at $25,30,35$, and $40^{\circ} \mathrm{C}$. At $0,1,3,5,7,14,21,50$, and 91 days after incubation, one petri dish per treatment was sampled and sclerotia were recovered by wet sieving. Viability of sclerotia was tested as described later. The experiment was performed twice.

Development of soil moisture curves. Soils from five lettuce fields each in the Salinas and the San Joaquin Valleys (Huron) were pooled by valley, pulverized manually, sieved (US number 10) to remove large particles, and airdried at $<30^{\circ} \mathrm{C}$. The air-dried soils were then used to develop soil moisture curves for estimating the amount of water required to achieve different water potentials. The soil samples were filled into steel rings on a pressure plate, saturated with water, and allowed to equilibrate overnight at $-0.01,-0.012,-0.02,-0.022,-0.04,-0.06,-0.08$, $-0.1,-0.15,-0.2,-0.3,-0.5$, and $-0.8 \mathrm{MPa}$. Then, each soil sample was weighed immediately (wet weight) and after drying at $85^{\circ} \mathrm{C}$ for $24 \mathrm{~h}$ (dry weight). The water content of each soil sample was calculated as percent water to dry weight of soil: $w c=$ (wet weight-dry weight)/dry weight $\times 100 \%$. Nonlinear regression model $w c=a \times(-w p)^{-\mathrm{b}}$ was first linearized as $\log (w c)=\log (a)-$ $b \times \log (-w p)$, and regression was performed with the REG Procedure in SAS (Rev. 9.1, SAS Institute Inc., Cary, NC) to fit the relationships between percent soil water content $(w c)$ and water potential $(w p)$ with a power model, to San Joaquin and Salinas Valley soils. The results were back transformed to nonlinear formats and used to estimate the amount of water needed to achieve the different water potentials tested in the experiments (Fig. 1).

Effects of soil temperature and moisture on survival of sclerotia. Soil samples from lettuce fields in the Salinas and the San Joaquin Valleys were pulverized, sieved, and air-dried as described previously. Half of the Huron soil was also autoclaved at $121^{\circ} \mathrm{C}$ twice with a $24-\mathrm{h}$ interval. Twenty sclerotia of each isolate were buried into $50 \mathrm{~g}$ of soil in a series of petri dishes. Sterilized distilled water was added to these plates to achieve 
water potentials of $-0.01,-0.05,-0.3$, and $-1.0 \mathrm{MPa}$ (estimated from the standard soil curves). Sclerotia were then incubated at 15,25 , and $35^{\circ} \mathrm{C}$. To maintain equilibrated soil moisture treatments during incubation, each petri dish was weighed at the beginning of incubation and every week thereafter. Water was replenished if the weight of any petri dish decreased more than $1 \mathrm{~g}$. After a $0,4,8$, and 12-week incubation, one petri dish from each treatment was sampled to recover sclerotia by wet sieving. Viability of sclerotia was then tested as described later. The experimental design was a split plot with temperature as the main factor and soil moisture as the subplot factor. The experiment was conducted three times.

Effects of oxygen concentration on survival of sclerotia. Because sclerotia of Sclerotinia spp. survive poorly in deeper soil profiles in the irrigated and flooded fields based on the results of the above experiments and previous studies $(15,25,29)$, experiments were conducted to test whether the poor survival of sclerotia at greater burial depths was due to anoxia. Two separate experiments were conducted. In the first experiment, soil samples were collected from a lettuce field in the Salinas Valley, bulked, pulverized, sieved, and air-dried at $<30^{\circ} \mathrm{C}$. Half of the soil sample was also autoclaved at $121^{\circ} \mathrm{C}$ for $1 \mathrm{~h}$ twice in $24-\mathrm{h}$. Forty sclerotia of each isolate were buried into $50 \mathrm{ml}$ of soil in a 100-ml flask. No water was added to the autoclaved soils while $10 \mathrm{ml}$ of sterilized distilled water was added to the nonautoclaved soils (equivalent to water potential about $-0.15 \mathrm{MPa}$ ). Sclerotia were then incubated at 15 and $25^{\circ} \mathrm{C}$ each with ultralow $(0.1 \%)$, low $(1 \%)$, and normal $(21 \%)$ oxygen concentrations in treatment chambers modified from pressure cookers. Each chamber had an inlet and an outlet. The ultralow oxygen treatment was achieved by passing nitrogen containing $0.1 \%$ oxygen from a nitrogen generator (Balston 75-7820, Parker Hannifin Co., Tewksburg, MA) continuously through the treatment chamber at a flow rate of 1 liter/min. The low oxygen treatment was achieved by passing a mix of the generated nitrogen and compressed air at a flow rate of 1 liter/min through the treatment chamber. Samples for the normal oxygen concentration treatment were exposed to ambient air. The oxygen concentrations for the ultralow and low oxygen treatments were measured at least five times during each incubation period using an oxygen analyzer (model 810, Illinois Instruments, Inc., Johnsburg, IL). After 2 and 4 weeks of incubation, a flask of sclerotia was sampled for each treatment. Sclerotia were retrieved using the wet sieving method and viability of 20 sclerotia was tested on PDA as later described. The experimental design constituted a split-split plot design with temperature as the main factor, oxygen as the subplot factor, and soil and moisture as sub-subplot factors. The experiment was conducted three times. Because significant differences were observed between autoclaved dry soil and nonautoclaved moist soil and the effects of oxygen levels were associated with nonautoclaved moist soil, a second experiment was conducted to determine whether the effects of oxygen levels were associated with soil type and autoclaving treatments. Because there was no significant difference between species and isolates in the first experiment, only BS014 of $S$. sclerotiorum was used in the second experiment. Soils collected from three different locations (clay, loam, and sandy soils from different parts of the Salinas Valley) were pulverized, sieved, and air-dried at $<30^{\circ} \mathrm{C}$. For each soil sample, one-half of the soil was autoclaved at $121^{\circ} \mathrm{C}$ twice in $24 \mathrm{~h}$, and the other half was used as is. Forty selected uniform sclerotia were buried into $50 \mathrm{ml}$ of soil in a 100-ml flask, and $10 \mathrm{ml}$ of sterilized distilled water was added into each flask. The sclerotia were incubated under different oxygen levels at $25^{\circ} \mathrm{C}$ for 4 weeks, 20 sclerotia were recovered and tested for viability on PDA as described later. The experiment was performed three times.

Viability tests on sclerotia of $S$. minor and $S$. sclerotiorum. Germination on PDA plates was used as the indicator of viability in all the experiments. Sclerotia were surface sterilized with $70 \%$ ethanol for $1 \mathrm{~min}$, rinsed in sterilized distilled water twice, and air-dried in a hood for 3 to $4 \mathrm{~h}$. Seven sclerotia were placed on each PDA plate (amended with $50 \mathrm{ppm}$ of streptomycin sulfate and chloramphenicol). The plates were incubated at $20^{\circ} \mathrm{C}$ in the dark and sclerotia were evaluated for germination every day beginning the 6th day and continued until the 10th day. Each day, the numbers of germinated sclerotia were counted and removed to prevent the developing colony from overgrowing the ungerminated sclerotia in the same plate. The total number of sclerotia that had germinated during the 10 days of incubation was expressed as a percent of the total plated.

Data analysis. Analysis of variance (ANOVA) was performed to test the fixed effects in all experiments using the Glimmix procedure in SAS because of its ability to handle binomial responses. The ratio of the number of germinated (events) to the total tested sclerotia (experiments) was considered the response variable in the model for all experiments.

For data from experiments determining survival of sclerotia in the field, fixed effects tested in the analysis included location (Salinas versus San Joaquin Valley), burial depth (5 and $15 \mathrm{~cm}$ ), pathogen species, burial duration (4, 8, 16, and 24 weeks), and their interactions. The experiments in 2000 and 2001 were considered as replications, and effects of year as well as its interaction with other factors was considered as random effects in the model. Because the germination rate of sclerotia showed little difference between either of the two fields in the same Valley or the two isolates of the same species, these factors were dropped from the final analysis and mean viability of sclerotia for year, burial duration, Valley, burial depth, and species are presented.

Temperature, sampling time, species, and their interactions were considered fixed effects in the data analysis for experiments on survival of sclerotia in dry autoclaved soil. Viability data were summed for the two isolates in each species because isolates within species were not a significant source of variance. Replication and its interactions with other factors were considered as random effects. Temperature, soil moisture, sample time, species and their interactions were considered as the fixed effects in the analysis of data from experiments determining survival of sclerotia in soils at different water potentials.

ANOVA of data on the survival of sclerotia at combinations of temperature, soil type, oxygen concentration, and sampling time considered these factors as fixed effects and replication, and its interactions with other factors as random effects. Because differences between the two species were insignificant, the germinated and total tested sclerotia were summed for each combination of oxygen, temperature, and soil in the final analysis.

\section{RESULTS}

Survival of sclerotia of $S$. minor and $S$. sclerotiorum. Viability of sclerotia of both species declined during the 24-week period of the experiments regardless of burial depth and Valleys. The length of time in the soil had a significant effect on the viability of sclerotia (Table 1). Significant differences between the San Joaquin and the Salinas Valleys, and between $S$. minor and $S$. sclerotiorum were observed (Table 1 ). The interactions of time $\times$ valley, time $\times$ species, and time $\times$ valley $\times$ species (Table 1 ) were significant. The viability of $S$. minor sclerotia declined more rapidly than that of $S$. sclerotiorum, and the difference between the two species was greater in the San Joaquin Valley than in the Salinas Valley (Fig. 2). Burial depth influenced the survival of sclerotia significantly along with the burial duration. Sclerotia at $15-\mathrm{cm}$ depth lost viability more rapidly than those at 5-cm depth, showing significant effect of interaction of depth $\times$ time (Table 1). The difference in sclerotium viability between the two depths was greater in the San Joaquin Valley than in the Salinas Valley, and greater for S. minor than for S. sclerotiorum (Fig. 2). Nearly $95 \%$ of sclerotia of $S$. minor at the $15 \mathrm{~cm}$ depth in the San Joaquin 
Valley did not germinate after 16 weeks of burial (Fig. 2). ANOVA revealed significant effects of interactions depth $\times$ time, depth $\times$ time $\times$ valley, depth $\times$ time $\times$ species, and depth $\times$ time $\times$ valley $\times$ species (Table 1 ).

Effects of temperature on survival of sclerotia. Temperature range tested $\left(25\right.$ to $\left.40^{\circ} \mathrm{C}\right)$ in this study had insignificant effect on

TABLE 1. Type III tests of fixed effects in analysis of variance on survival of sclerotia of Sclerotinia minor and S. sclerotiorum in the field

\begin{tabular}{lcrrr}
\hline Effect $^{\mathrm{a}}$ & Num DF & Den DF & $F$ value & \multicolumn{1}{r}{$P>F^{\mathrm{b}}$} \\
\hline Time & 3 & 32.00 & 76.29 & $<0.0001$ \\
Valley (val) & 1 & 4.10 & 15.38 & 0.0164 \\
Time $\times$ val & 3 & 32.00 & 31.36 & $<0.0001$ \\
Depth & 1 & 4.10 & 5.21 & 0.0829 \\
Time $\times$ depth & 3 & 32.00 & 7.67 & 0.0005 \\
Val $\times$ depth & 1 & 4.10 & 5.21 & 0.0829 \\
Time $\times$ val $\times$ depth & 3 & 32.00 & 8.47 & 0.0003 \\
Species & 1 & 4.08 & 52.79 & 0.0018 \\
Time $\times$ species & 3 & 32.00 & 37.36 & $<0.0001$ \\
Val $\times$ species & 1 & 4.08 & 3.92 & 0.1174 \\
Time $\times$ val $\times$ species & 3 & 32.00 & 4.56 & 0.0090 \\
Depth $\times$ species & 1 & 4.08 & 2.08 & 0.2209 \\
Time $\times$ depth $\times$ species & 3 & 32.00 & 6.02 & 0.0023 \\
Val $\times$ depth $\times$ species & 1 & 4.08 & 0.00 & 0.9847 \\
Time $\times$ val $\times$ depth $\times$ species & 3 & 32.00 & 9.98 & $<0.0001$ \\
\hline
\end{tabular}

a Time = burial duration $(4,8,16$, and 24 weeks $)$, depth $=$ burial depth $(5$ and $15 \mathrm{~cm}$ ), and val = the Salinas or the San Joaquin Valley, species $=S$. minor and $S$. sclerotiorum.

${ }^{\mathrm{b}}$ A value smaller than 0.05 indicates a significant effect of the factor.
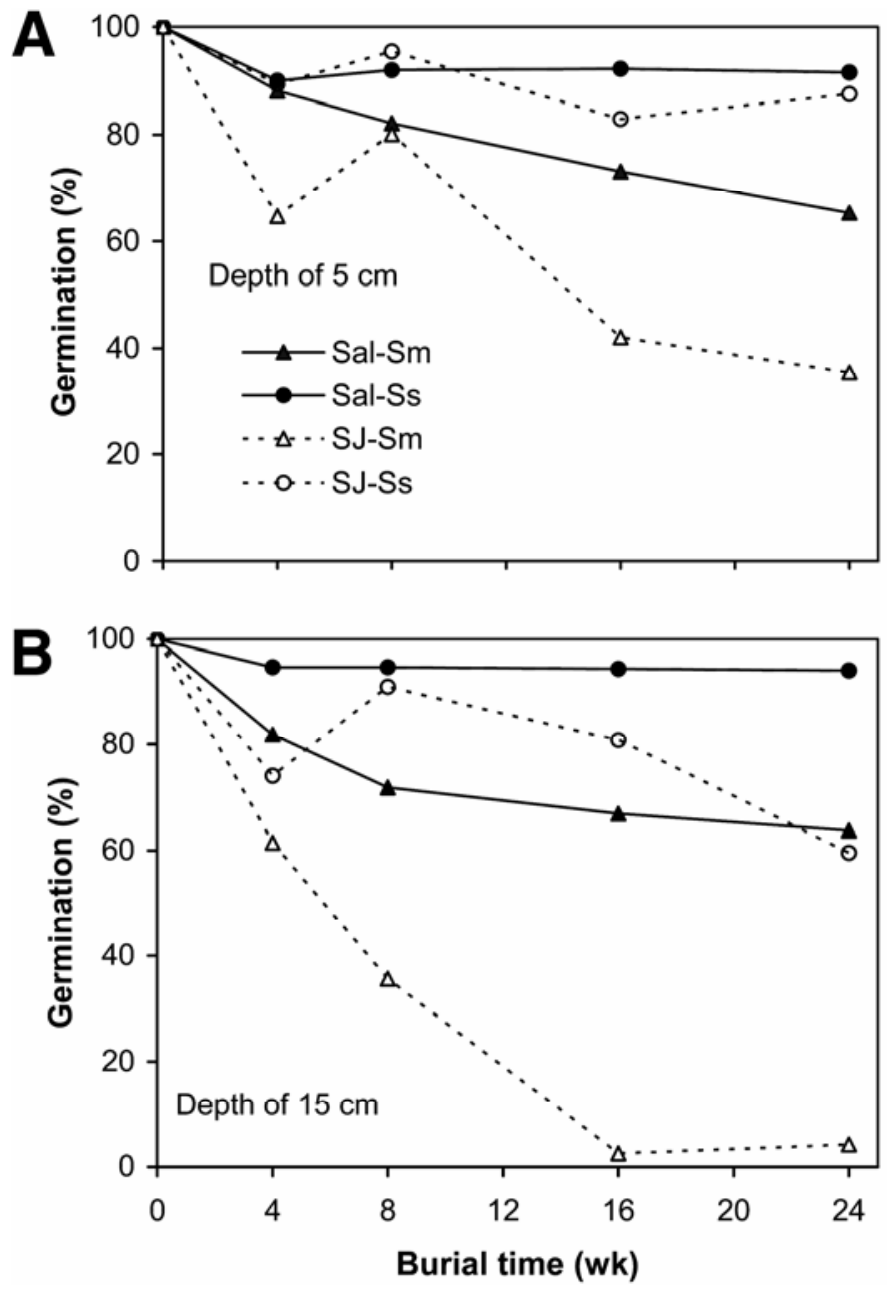

Fig. 2. Germination of sclerotia of Sclerotinia minor and S. sclerotiorum after burial at 5-cm (A) and 15-cm (B) depths in fields in the Salinas and San Joaquin Valleys. the survival of sclerotia of the two Sclerotinia species. During the 91 days of incubation, viability of sclerotia remained high (the lowest germination rate was about $92 \%$ ) regardless of the incubation temperature and the Sclerotinia species (Fig. 3). The effects of incubation time was not significant $(P=0.30$ to 0.99$)$ and the differences among the temperature treatments were small although statistically significant $(P=0.02)$.

Effects of soil temperature and moisture on survival of sclerotia. Equilibrated water potentials were maintained during any 2 -week incubation period at 15 and $25^{\circ} \mathrm{C}$. Although a few petri dishes incubated at $35^{\circ} \mathrm{C}$ lost $>1.0 \mathrm{~g}$ of water during a 2week period, the total weight loss was less than $0.5 \mathrm{~g}$ for most petri dishes, and the water potentials did not deviate much from the designed values during the entire experiment. ANOVA revealed significant effects of incubation temperature, soil moisture, species, sampling time, and temperature $\times$ time, temperature $\times$ moisture, species $\times$ time, and temperature $\times$ species $\times$ moisture interactions (data not shown). The higher the temperature, the faster was the decline in viability of sclerotia of both species except at $-1.0 \mathrm{MPa}$ for $S$. sclerotiorum (Fig. 4). Effects of soil moisture was only significant at $35^{\circ} \mathrm{C}$, but not at 15 or $25^{\circ} \mathrm{C}$. Regardless of soil moisture, sclerotia of both species remained viable over the 12 -week incubation at both 15 and $25^{\circ} \mathrm{C}$. At $35^{\circ} \mathrm{C}$, the viability of sclerotia declined rapidly at higher soil moisture. Fewer than $5 \%$ of sclerotia remained viable after an 8 -week incubation at $-0.3 \mathrm{MPa}$ or higher, and the percentage of viable sclerotia decreased to near-zero after 12-weeks incubation (Fig. 4).

Effects of temperature, soil, and oxygen concentration on survival of sclerotia. ANOVA showed significant effects of incubation temperature, oxygen concentration, soil moisture, sampling time, and temperature $\times$ oxygen, temperature $\times$ soil, oxygen $\times$ soil, temperature $\times$ time, and soil $\times$ time interactions (Table 2 ). In the dry autoclaved soil, viability of sclerotia changed little over the 4-week incubation duration regardless the different combinations of temperature and oxygen (Fig. 5) even though viability of sclerotia exposed to different oxygen concentrations were significantly different at $25^{\circ} \mathrm{C}$. In contrast, viability of sclerotia buried in wet nonautoclaved soil declined over time and was affected significantly by incubation temperature and oxygen concentration. The viability of sclerotia declined most rapidly at $0.1 \%$ oxygen and $25^{\circ} \mathrm{C}$ (Fig. 5) with $96.7 \%$ ( \pm 1.3 standard error of the mean) of sclerotia losing viability within 2 weeks of incubation and $98.3 \%$

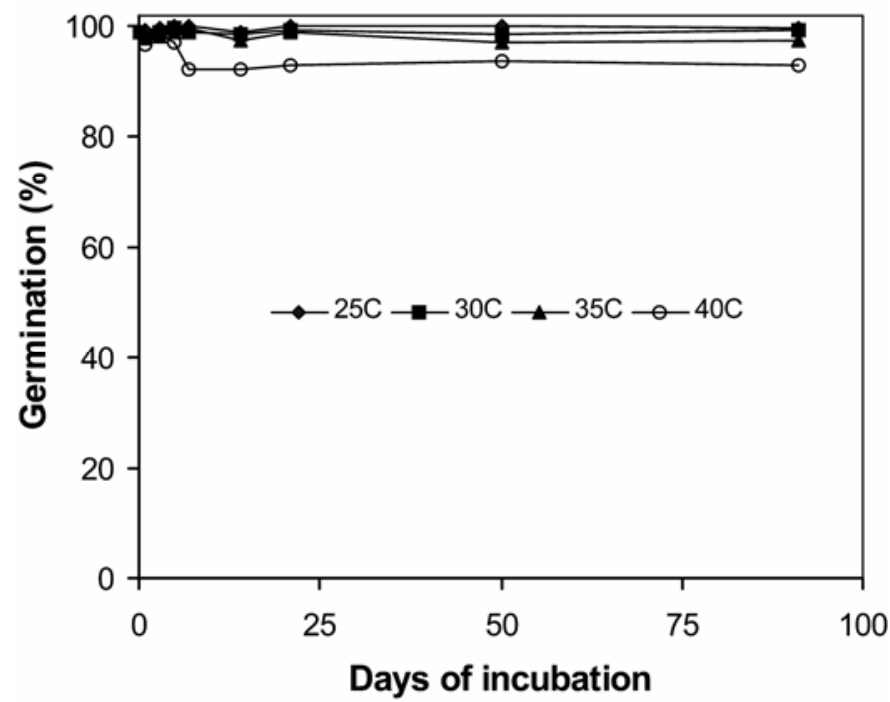

Fig. 3. Germination of sclerotia of Sclerotinia minor and S. sclerotiorum after incubation in autoclaved dry soil at different temperatures in growth chambers. The responses of both species were similar, therefore means of four isolates of the two species are presented. 
$( \pm 0.94$ standard error of the mean) of sclerotia losing viability in 4 weeks (Fig. 5).

Reduced oxygen and autoclave treatments affected the survival of sclerotia significantly among the different soil types (data not shown). Neither the soil type nor its interaction with oxygen concentration was statistically significant (data not shown). Regardless of the soil types, the sclerotia survived better at ambient oxygen concentration in the autoclaved soils than at reduced oxygen concentrations and in the nonautoclaved soils (data not shown).

\section{DISCUSSION}

Sclerotia of $S$. sclerotiorum survived significantly better than $S$. minor under the soil conditions evaluated in the field study. Among the many factors that affect the survival of sclerotia of Sclerotinia species in the complex soil environment, soil tempera-
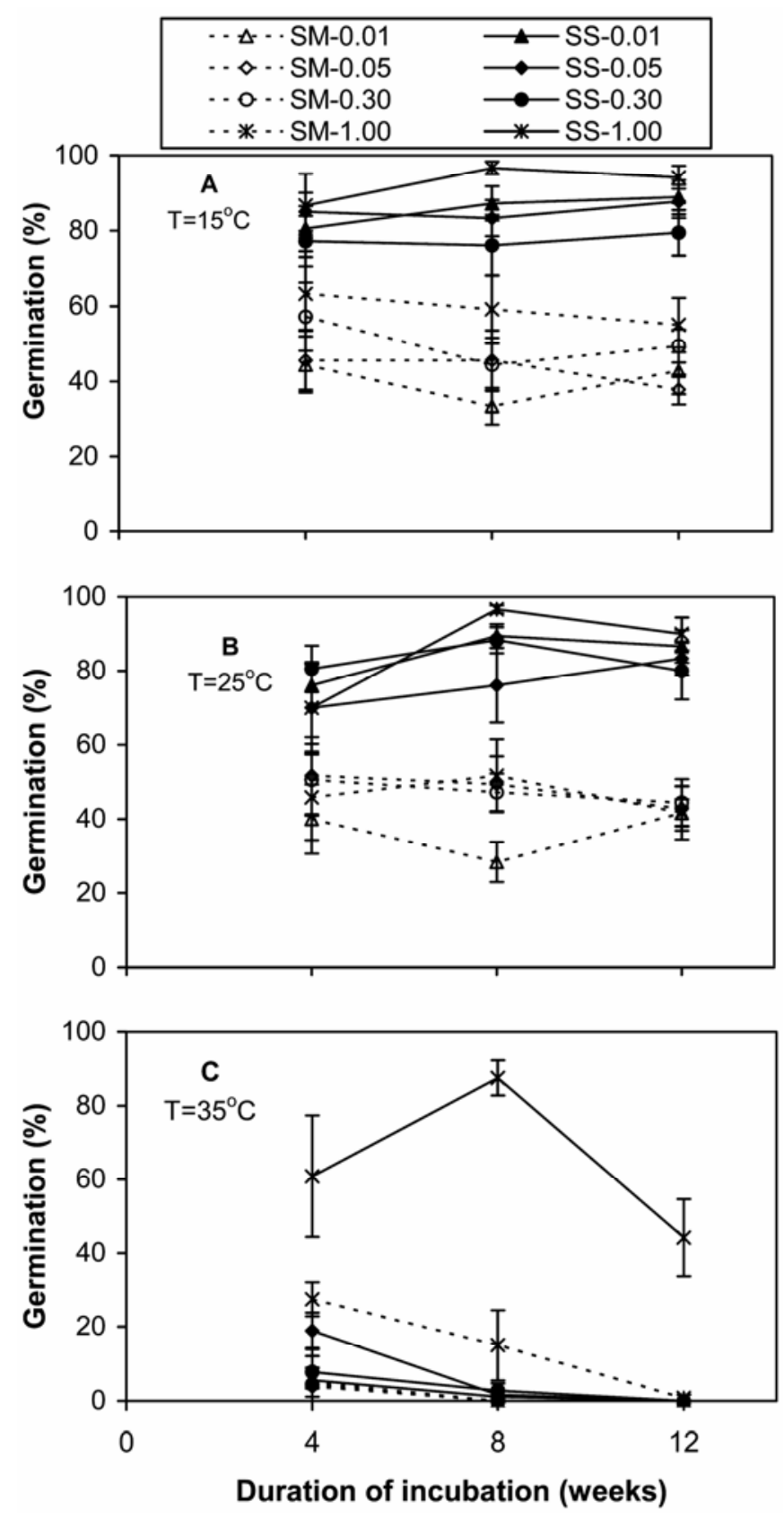

Fig. 4. Germination of sclerotia of Sclerotinia minor and S. sclerotiorum in soils after incubation under different combinations of temperature $(15,25$, and $\left.35^{\circ} \mathrm{C}\right)$ and moisture $(-0.01,-0.05,-0.30$, and $-1.00 \mathrm{MPa})$. ture and moisture coupled with oxygen concentration play a significant role. While the effects of soil temperature and moisture on survival of Sclerotinia spp. either singly or in combination have been studied extensively (3-5,9,15,17,18,20,23,25,26,29, $42,44)$, the potential role of oxygen deficiency on the survival of sclerotia was previously untested. Regardless of the temperature and oxygen levels, consistently high numbers of sclerotia of both species survived in dry soils. In contrast, viability of sclerotia of both species declined in wet soils. This decline was more evident and rapid in the ultralow oxygen environments than under ambient oxygen conditions. These responses were identical in all soil types tested in this study. Previous studies, save for two $(20,25)$ had studied the effects of temperature and soil moisture on germination of individual Sclerotinia species. In contrast, this study compared the survival of sclerotia of both Sclerotinia species. This is also the first report of comparing the responses of two related species to combinations of soil temperature, moisture, and oxygen.

TABLE 2. Type III tests of fixed effects in analysis of variance on survival of sclerotia of Sclerotinia minor and S. sclerotiorum

\begin{tabular}{lcrrr}
\hline Effect $^{\mathrm{a}}$ & Num DF & Den DF & $F$ value & $P>F^{\mathrm{b}}$ \\
\hline Temp & 1 & 3.30 & 16.53 & 0.0223 \\
Oxygen & 2 & 32.57 & 45.41 & $<0.0001$ \\
Temp $\times$ oxygen & 2 & 32.58 & 4.01 & 0.0277 \\
Soil & 1 & 38.06 & 450.53 & $<0.0001$ \\
Temp $\times$ soil & 1 & 38.07 & 6.67 & 0.0138 \\
Oxygen $\times$ soil & 2 & 32.50 & 25.43 & $<0.0001$ \\
Temp $\times$ oxygen $\times$ soil & 2 & 32.50 & 0.56 & 0.5774 \\
Time & 1 & 120.00 & 7.24 & 0.0082 \\
Temp $\times$ time & 1 & 120.00 & 4.26 & 0.0411 \\
Oxygen $\times$ time & 2 & 120.00 & 1.30 & 0.2764 \\
Temp $\times$ oxygen $\times$ time & 2 & 120.00 & 0.08 & 0.9262 \\
Soil $\times$ time & 1 & 120.00 & 5.89 & 0.0167 \\
Temp $\times$ soil $\times$ time & 1 & 120.00 & 1.99 & 0.1605 \\
Oxygen $\times$ soil $\times$ time & 2 & 120.00 & 2.12 & 0.1245 \\
Temp $\times$ oxygen $\times$ soil $\times$ time & 2 & 120.00 & 0.08 & 0.9271 \\
\hline
\end{tabular}

a Time = incubation duration ( 2 and 4 weeks), Temp = incubation temperature $\left(15\right.$ and $25^{\circ} \mathrm{C}$ ), soil $=$ soils used for burial of sclerotia (nonautoclaved wet versus autoclaved dry soils), and oxygen = oxygen concentration during incubation $(0.1,1.0$, and $21 \%)$.

b A value smaller than 0.05 indicates a significant effect of the factor.

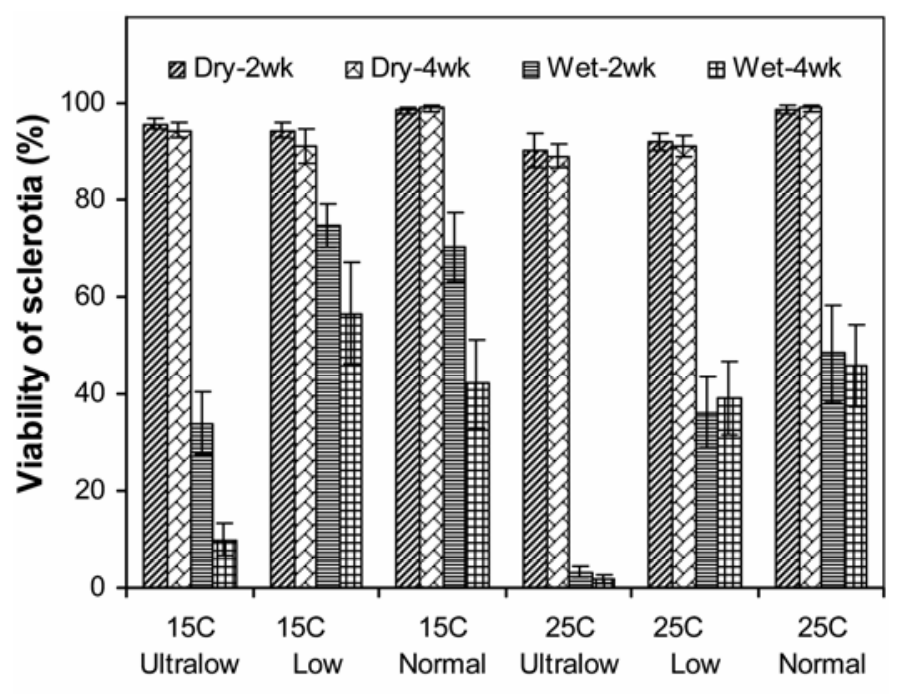

Temperature and oxygen treatments

Fig. 5. Survival of sclerotia of Sclerotinia minor and S. sclerotiorum in autoclaved dry versus nonautoclaved wet soils under different combinations of oxygen concentration (ultralow $=0.1 \%$, low $=1.0 \%$, and normal $=21 \%$ ) and temperature $\left(15\right.$ and $\left.25^{\circ} \mathrm{C}\right)$. The means and standard errors of four isolates of the two species are presented because of small and insignificant $(P>0.05)$ differences among isolates. 
Under the warm conditions of the San Joaquin Valley (at $15 \mathrm{~cm}$ below the soil surface, the average soil temperature over a period from 15 June to 15 September ranged from 23.5 to $30.3^{\circ} \mathrm{C}$ among 10 nearby California Irrigation Management Information System's weather stations during 1995 to 1997), sclerotia of S. sclerotiorum survived significantly better than sclerotia of $S$. minor. More than $95 \%$ sclerotia of S. minor failed to germinate after a 16-week burial in the San Joaquin Valley even though previous reports (6) generally considered the sclerotia to survive in soil over multiple years. Experiments reported here were conducted in commercial production fields and the findings in this study and those of Matheron and Porchas (25) are remarkably consistent even though the soil temperature and moisture in this study may not be comparable with those in Arizona during summer. Matheron and Porchas (25) also found that $S$. minor declined faster than $S$. sclerotiorum and more so under warm than cool conditions. This study at least partially explained why $S$. minor has not established as a major pathogen on lettuce in the San Joaquin Valley even after its presence in the Valley has been recorded for decades. Because lettuce is usually not grown in the San Joaquin Valley from April to October each year when soil temperature is usually above $25^{\circ} \mathrm{C}$, few sclerotia of $S$. minor can survive the summer to cause disease on the next crop of lettuce. More generally, this finding provides a more plausible rationale for the geographical distribution of the two species in the world. S. minor is present mostly in areas with cool climates, such as the Salinas Valley where the soil temperature is usually lower than $20^{\circ} \mathrm{C}$ even during the summer and S. sclerotiorum is distributed more widely throughout the world, including places like the San Joaquin Valley with hot summers (32).

Significantly more sclerotia of both species survived at $5 \mathrm{~cm}$ depth than at $15 \mathrm{~cm}$ depth. These results are similar to those obtained by several previous studies $(15,23,25)$. This differed from the report by Adams (5) that more sclerotia survived in deeper soil profiles than those on the surface or near the surface. This difference may have resulted from different approaches employed in the two studies as the newly produced sclerotia were not excluded nor were the fields irrigated at frequencies similar to California commercial fields in the study by Adams (5). Lower survival of $S$. minor in deeper soil profiles $(3,23)$ was used as a rationale to develop deep plowing as a disease management strategy in the early 1980s. However, Subbarao et al. (41) determined that while the expected overall reduction in the number of sclerotia of $S$. minor was achieved immediately following deep plowing, the tillage operations associated with deep plowing also tended to distribute sclerotia horizontally and led to a less aggregated pattern. This led to increased lettuce drop in lettuce crops following deep plowing (41). The results from the current study suggest that the survival of sclerotia is less affected by burial depths at cooler temperatures. This may also explain the ineffectiveness of deep plowing in the Salinas Valley with soil temperature mostly lower than $20^{\circ} \mathrm{C}$.

Under ambient oxygen levels, a combination of high soil temperature and soil moisture significantly reduced survival of sclerotia of both Sclerotinia species. The effects of temperature and moisture on survival were only significant when they were tested together. High soil moisture or high temperature alone showed very little effect on the survival of both Sclerotinia species. The results on effects of temperature were consistent with the reports by Adams (5) who found sclerotia of $S$. minor can survive well at a soil temperature up to $35^{\circ} \mathrm{C}$, and concluded that soil temperature alone does not play a major role in the natural decline in populations of the fungus. The results on soil moisture obtained by Adams (5) where fewer sclerotia of $S$. minor survived at extremely low water potential were inconsistent with the results obtained in this study as well as those by Abawi et al. (3). The survival at extremely low water potential may mimic the survival of sclerotia above soil surface without vegetation coverage, but the survival of sclerotia during rotation with nonhost crops may be better estimated by results obtained with the high soil water potential that are common in irrigated fields. Unlike in the previous studies by Abawi et al. (3) who found significant difference between two different soils, no significant difference was found in this study among autoclaved and nonautoclaved soil collected from the San Joaquin Valley, and nonautoclaved (clay) soil collected from the Salinas Valley at similar water potentials. Therefore, the rapid decline in the viability of sclerotia at high soil moisture and temperature observed in this study could not be attributed to the activity of certain soil organisms, which has been speculated repeatedly $(3,5,6,23,25)$.

The effect of oxygen concentration on survival of sclerotia under conditions tested in this study was quite remarkable. Regardless of the origin of soils that were autoclaved or not, low oxygen concentration significantly reduced the survival of sclerotia of both Sclerotinia species. Lowest survival of sclerotia of both Sclerotinia species at ultralow oxygen occurred at $25^{\circ} \mathrm{C}$ in soils with high soil moisture, and the effects of oxygen were smaller at $15^{\circ} \mathrm{C}$ and low soil moisture. More than $96 \%$ of sclerotia lost viability within a 2 -week period at ultralow oxygen concentration $(0.1 \%)$ with the soil temperature at $25^{\circ} \mathrm{C}$ and water content at $20 \%$ (vol/vol water potential at about $-0.1 \mathrm{MPa}$ ). This reduction was more dramatic than that caused by high soil temperature and moisture at ambient oxygen level. Oxygen concentration is extremely low at depths $\geq 5 \mathrm{~mm}$ from the surface in flooded fields (34), and negatively related to the pore space filled by water (36), and is usually lowest around the depth of 15 to $20 \mathrm{~cm}$ in drip irrigated fields (37). Given this, the results suggested that oxygen deficiency deep in irrigated or flooded soils may be a major cause of enhanced degradation of sclerotia $(25,29)$. This is the first report of destructive effects of oxygen deficiency or anoxia on the soilborne sclerotia of fungi, but similar results were reported on mycelium of wood-decay fungi. During 16 weeks of incubation under low oxygen conditions achieved with either argon or nitrogen gas, $80 \%$ of mycelium inocula of Coniophora puteana and $76 \%$ of Antrodia vaillantii lost viability (43). A direct and detrimental effect of soil waterlogging was also reported on survival of Collybia fusipes both under controlled conditions and in forest stands (12). A better understanding of the mechanisms behind the enhanced degradation of sclerotia deep in the irrigated or flooded soils will help design improved strategies for the management of diseases caused by S. minor, S. sclerotiorum, and other soil-borne pathogens.

\section{ACKNOWLEDGMENTS}

We thank B. Mackey, the Statistician General for USDA at Pacific West Area, Albany, CA, for helpful suggestions on data analyses and interpretations. This research was funded by the California Lettuce Research Board.

\section{LITERATURE CITED}

1. Abawi, G. S., and Grogan, R. G. 1975. Source of primary inoculum and effects of temperature and moisture on infection of beans by Whetzeliniasclerotiorum. Phytopathology 65:300-309.

2. Abawi, G. S., and Grogan, R. G. 1979. Epidemiology of diseases caused by Sclerotinia species. Phytopathology 69:899-904

3. Abawi, G. S., Grogan, R. G., and Duniway, J. M. 1985. Effect of water potential on survival of sclerotia of Sclerotinia minor in two California soils. Phytopathology 75:217-221.

4. Adams, P. B. 1975. Factors affecting survival of Sclerotinia sclerotiorum in soil. Plant Dis. Rep. 59:599-603.

5. Adams, P. B. 1987. Effects of soil temperature, moisture, and depth on survival and activity of Sclerotinia minor, Sclerotium cepivorum, and Sporidesmium sclerotivorum. Plant Dis. 71:170-174.

6. Adams, P. B., and Ayers, W. A. 1979. Ecology of Sclerotinia species. Phytopathology 69:896-899.

7. Adams, P. B., and Tate, C. J. 1975. Factors affecting lettuce drop caused by Sclerotinia sclerotiorum. Plant Dis. Rep. 59:140-143. 
8. Ben-Yephet, Y. A., Bitton, S., and Greenberger, A. 1986. Control of lettuce drop disease, caused by Sclerotinia sclerotiorum, with methamsodium soil treatment and foliar application of benomyl. Plant Pathol. 35:146-151.

9. Ben-Yephet, Y., Genizi, A., and Siti, E. 1993. Sclerotial survival and apothecial production by Sclerotinia sclerotiorum following outbreaks of lettuce drop. Phytopathology 83:509-513.

10. Boland, G. J., and Hall, R. 1994. Index of plant hosts of Sclerotiniasclerotiorum. Can. J. Plant Pathol. 16:93-108.

11. Budge, S. P., Mcquilken, M. P., Fenlon, J. S., and Whipps, J. M. 1995. Use of Coniothyrium-minitans and Gliocladium-virens for biologicalcontrol of Sclerotinia-sclerotiorum in glasshouse lettuce. Biol. Control 5:513-522.

12. Camy, C., Dreyer, E., Delatour, C., and Marçais, B. 2003. Responses of the root rot fungus Collybia fusipes to soil waterlogging and oxygen availability. Mycol. Res. 107:1103-1109.

13. Davis, W. H. 1925. Drop of Chinese cabbage and our common cabbage caused by Sclerotinia sclerotiorum (Lib.) massee (Sclerotinia libertiana Fckl.). Phytopathology 15:249-259.

14. Dillard, H. R., and Grogan, R. G. 1985. Relationship between sclerotial spatial pattern and density of Sclerotinia-minor and the incidence of lettuce drop. Phytopathology 75:90-94.

15. Duncan, R. W., Fernando, W. G. D., and Rashid, K. Y. 2006. Time and burial depth influencing the viability and bacterial colonization of sclerotia of Sclerotinia sclerotiorum. Soil Biol. Biochem. 38:275-284.

16. Ekins, M. G., Aitken, E. A. B., and Goulter, K. C. 2002. Carpogenic germination of Sclerotinia minor and potential distribution in Australia. Australas. Plant Pathol. 31:259-265.

17. Gracia-Garza, J. A., Reeleder, R. D., and Paulitz, T. C. 1997. Degradation of sclerotia of Sclerotinia sclerotiorum by fungus gnats (Bradysia coprophila) and the biocontrol fungi Trichoderma spp. Soil Biol. Biochem. 29:123-129.

18. Grogan, R. G., and Abawi, G. S. 1975. Influence of water potential on growth and survival of Whetzelinia-sclerotiorum. Phytopathology 65:122128.

19. Grogan, R. G., Sall, M. A., and Punja, Z. K. 1980. Concepts for modeling root infection by soilborne fungi. Phytopathology 70:361-363.

20. Hao, J. J., Subbarao, K. V., and Duniway, J. M. 2003. Germination of Sclerotinia minor and $S$. sclerotiorum sclerotia under various soil moisture and temperature combinations. Phytopathology 93:443-450.

21. Hawthorne, B. T. 1973. Production of apothecia of Sclerotinia-minor. N.Z. J. Agric. Res. 16:559-560.

22. Hawthorne, B. T. 1976. Observations on development of apothecia of Sclerotinia minor Jagger in field. N.Z. J. Agric. Res. 19:383-386.

23. Imolehin, E. D., and Grogan, R. G. 1980. Factors affecting survival of sclerotia, and effects of inoculum density, relative position, and distance of sclerotia from the host on infection of lettuce by Sclerotinia-minor. Phytopathology 70:1162-1167.

24. Jarvis, W. R., and Hawthorne, B. T. 1972. Sclerotinia minor on lettuce: Progress of an epidemic. Ann. Appl. Boil. 70:207-214.

25. Matheron, M. E., and Porchas, M. 2005. Influence of soil temperature and moisture on eruptive germination and viability of sclerotia of Sclerotinia minor and S. sclerotiorum. Plant Dis. 89:50-54.

26. McQuilken, M. P., Mitchell, S. J., Budge, S. P., Whipps, J. M., Fenlon, J. S., and Archer, S. A. 1995. Effect of Coniothyrium minitans on sclerotial survival and apothecial production of Sclerotinia sclerotiorum in fieldgrown oilseed rape. Plant Pathol. 44:883-896.

27. Melzer, M. S., and Boland, G. J. 1994. Epidemiology of lettuce drop caused by Sclerotinia minor. Can. J. Plant Pathol. 16:170-176.

28. Melzer, M. S., Smith, E. A., and Boland, G. J. 1997. Index of plant hosts of Sclerotinia minor. Can. J. Plant Pathol. 19:272-280.

29. Moore, W. D. 1949. Flooding as a means of destroying the sclerotia of Sclerotinia sclerotiorum. Phytopathology 39:920-927.

30. Newton, C. H., and Sequeira, L. 1972. Ascospores as the primary infective propagule of Sclerotinia sclerotiorum in Wisconsin. Plant Dis. Rep. 56:798-802.

31. Patterson, C. L., and Grogan, R. G. 1985. Differences in epidemiology and control of lettuce drop caused by Sclerotinia minor and Sclerotinia sclerotiorum. Plant Dis. 69:766-770.

32. Purdy, L. H. 1979. Sclerotinia sclerotiorum: History, disease and symptomatology, host range, geographic distribution and impact. Phytopathology 69:875-880.

33. Rabeendran, N., Jones, E. E., Moot, D. J, and Stewart, A. 2006. Biocontrol of Sclerotinia lettuce drop by Coniothyrium minitans and Trichoderma hamatum. Biol. Control 39:352-362.

34. Ratering, S., and Schnell, S. 2000. Localization of iron-reducing activity in paddy soil by profile studies. Biogeochemistry 48:341-365.

35. Schwartz, H. F., and Steadman, J. R. 1978. Factors affecting sclerotium populations of, and apothecium production by Sclerotinia sclerotiorum. Phytopathology 68:383-388.

36. Sierra, J., and Renault, P. 1998. Oxygen concentration in a hydromorphic soil. Soil Sci. Soc. Am. J. 62:1398-1405.

37. Silberbush, M., Gornat, B., and Goldberg, D. 1979. Effect of irrigation from a point source (trickling) on oxygen flux and on root extension in the soil. Plant Soil 52:507-514.

38. Subbarao, K. V. 1997. Lettuce Drop. Pages 19-21 in: Compendium of Lettuce Diseases. R. M Davis, K. V. Subbarao, R. N. Raid, and E. A. Kurtz, eds. American Phytopathological Society, St. Paul, MN.

39. Subbarao, K. V. 1998. Progress toward integrated management of lettuce drop. Plant Dis. 82:1068-1078.

40. Subbarao, K. V., Dacuyan, S., Koike, S. T., and Jackson, L. E. 1994. Evaluation of three quantitative assays for Sclerotinia minor. Phytopathology 84:1471-1475.

41. Subbarao, K. V., Koike, S. T., and Hubbard, J. C. 1996. Effects of deep plowing on the distribution and density of Sclerotinia minor sclerotia and lettuce drop incidence. Plant Dis. 80:28-33.

42. Swaminathan, J., McLean, K. L., Pay, J. M., and Stewart, V. 1999. Soil solarisation: A cultural practice to reduce viability of sclerotia of Sclerotinia sclerotiorum in New Zealand soils. N.Z. J. Crop Hort. 27:331335.

43. Tavzes, C., Pohleven, F., and Koestler, R. J. 2001. Effect of anoxic conditions on wood-decay fungi treated with argon or nitrogen. Int. Biodeter. Biodeg. 47:225-231.

44. Vannacci, G., Triolo, E., and Materazzi, A. 1988. Survival of Sclerotinia minor Jagger sclerotia in solarized soil. Plant Soil 109:49-55.

45. Wu, B. M., and Subbarao, K. V. 2006. Analyses of lettuce drop incidence and population structure of Sclerotinia sclerotiorum and S. minor. Phytopathology 96:1322-1329.

46. Young, P. A., and Morris, H. E. 1927. Sclerotinia wilt of sunflowers. Montana AES Bull. 208. 